\title{
Enhancing LVRT Capability of DFIG-Based Wind Turbine Systems with SMES Series in the Rotor Side
}

\author{
Xiao Zhou, Yuejin Tang, and Jing Shi \\ State Key Laboratory of Advanced Electromagnetic Engineering and Technology, R\&D Center of Applied Superconductivity, \\ Huazhong University of Science and Technology, Wuhan 430074, China
}

Correspondence should be addressed to Jing Shi; shijing@mail.hust.edu.cn

Received 29 March 2017; Accepted 7 May 2017; Published 13 June 2017

Academic Editor: Lei Chen

Copyright (C) 2017 Xiao Zhou et al. This is an open access article distributed under the Creative Commons Attribution License, which permits unrestricted use, distribution, and reproduction in any medium, provided the original work is properly cited.

The necessary Low Voltage Ride Through (LVRT) capability is very important to wind turbines. This paper presents a method to enhance LVRT capability of doubly fed induction generators- (DFIGs-) based wind turbine systems with series superconducting magnetic energy storage (SMES) in the rotor side. When grid fault occurs, series SMES in the rotor side is utilized to produce a desired output voltage and absorbs energy. Compared with other methods which enhance LVRT capability with Superconducting Fault-Current Limiter-Magnetic Energy Storage System (SFCL-MESS), this strategy can control the output voltage of SMES to suppress the transient AC voltage component in the rotor directly, which is more effective and rapid. Theoretical study of the DFIG under low voltage fault is developed; the simulation results are operated by MATLAB/Simulink.

\section{Introduction}

Wind energy generation has experienced a fast development in the last two decades [1]. DFIG is the most widely used wind turbine, but it is vulnerable to low voltage fault. Many wind turbines trip off from the grid due to the lack of LVRT capability [2].

There are many enhanced ways to solve this problem. Crowbar is a commonly used protection method to implement the LVRT capability [3-5]; it can effectively suppress overvoltage and overcurrent but it needs to absorb a large amount of reactive power from the grid, which will do harm to the grid. Improving control strategy of grid converter or rotor converter has been studied by many researchers [6-8], but it cannot work effectively when deep voltage drop occurs. Energy storage device is suitable for dynamic matching of intermittent wind power. The use of supercapacitors or batteries for WTGs has been studied by some researchers [911]. SMES used in DFIGs to reduce power fluctuation and alleviate the influence on power quality has been studied in some papers [12]. The application of SFCL-SMES in the rotor side of the DFIG has been carried out. But it is connected with the DFIG through a three-phase diode rectifier; thus the SFCL-MES is inserted into rotor circuit as an impedance, which will not provide help in enhancing the controllability of the RSC.

This paper presents a new method to enhance LVRT capability of DFIG with SMES. SMES, with its high efficiency and quick response ability to power compensation, could be a good choice for ESD in DFIG. Most studies applied ESD to solve the problem which are usually in parallel with the DC side. The proposed method in this paper is to generate a desired output voltage utilizing series SMES in the rotor side. Through the analysis of the rotor side voltage under low voltage fault, counter-electromotive force generated by SMES can counteract overvoltage and then overcurrent quickly and effectively. The mathematical model of DFIG will be illustrated first. Then, behavior of the DFIG in normal situation and under low voltage fault will be analyzed and the control strategy of VSC-SMES will be introduced.

\section{Math Model of DFIG}

The stator windings of the DFIG wind turbine are directly connected to the grid. The rotor winding is connected to the grid via back-to-back transformers, where the converter near the grid side is called grid sided converter (GSC) while 
near the rotor side converter it is called rotor sided converter (RSC). The stator voltage is provided by the grid. The rotor voltage is provided by the back-to-back transformers, which can be adjusted in frequency, phase, and amplitude.

In this paper, the control system is implemented considering a stator voltage oriented (SVO) control philosophy in the $d / q$ reference frame [13]. In this kind of systems, the $d / q$ axes are aligned with the stator voltage. Thus, the park model of the DFIG can be expressed as follows:

$$
\begin{aligned}
& u_{d r}=R_{r} i_{d r}+\frac{d \psi_{d r}}{d t}-\left(\omega_{1}-\omega_{r}\right) \psi_{q r} \\
& u_{q r}=R_{r} i_{q r}+\frac{d \psi_{q r}}{d t}+\left(\omega_{1}-\omega_{r}\right) \psi_{d r} \\
& u_{d s}=R_{s} i_{d s}+\frac{d \psi_{d s}}{d t}-\omega_{1} \psi_{q s} \\
& u_{q s}=R_{s} i_{q s}+\frac{d \psi_{q s}}{d t}+\omega_{1} \psi_{d s} \\
& \psi_{d s}=L_{s} i_{d s}+L_{m} i_{d r} \\
& \psi_{q s}=L_{s} i_{q s}+L_{m} i_{q r} \\
& \psi_{d r}=L_{m} i_{d s}+L_{r} i_{d r} \\
& \psi_{q r}=L_{m} i_{q s}+L_{r} i_{q r}
\end{aligned}
$$

where $\psi$ is the magnetic flux, $L$ is the inductances, $u$ and $i$ are voltage and current, respectively, $R$ is the resistance, subscripts $s, r, m$ represent the stator, rotor, and mutual, respectively, and $\omega_{1}$ and $\omega_{r}$ are the synchronous and rotating angular frequencies $\left(\omega_{s}=\omega_{1}-\omega_{r}\right)$.

Once there is a grid fault, the stator voltage will change immediately because it is connected to the grid directly. But, according to the principle of flux conservation, the amplitude of stator flux will not transition. At the moment when the voltage drops, the stator flux linkage contains an AC component and a DC component, which will induce overvoltage in rotor side with different frequencies.

As analyzed in [14], the rotor back EMF voltage can be expressed as follows:

$$
\begin{aligned}
u_{r d q}= & j \frac{L_{m}}{L_{s}} \omega_{s} \psi_{s 2 d q} \\
& -j \frac{L_{m}}{L_{s}} \omega_{r}\left(\psi_{s 0 d q}-\psi_{s 2 d q}\right) e^{-\sigma t} e^{-j \omega_{s} t},
\end{aligned}
$$

where $\psi_{s 0 d q}$ and $\psi_{s 2 d q}$ are normal-state stator flux and faultstate stator flux. The rotor back EMF voltage is mainly decided by part two of (2) because the slip frequency is much smaller than rotor frequency. And the second part in (2) is decided by the stator flux which can be several times the default value.

\section{Methodology of DFIG and SMES Model}

Unlike SFCL-MES, this paper controls the SMES output voltage through converter switch control, which could suppress the overvoltage in rotor side.

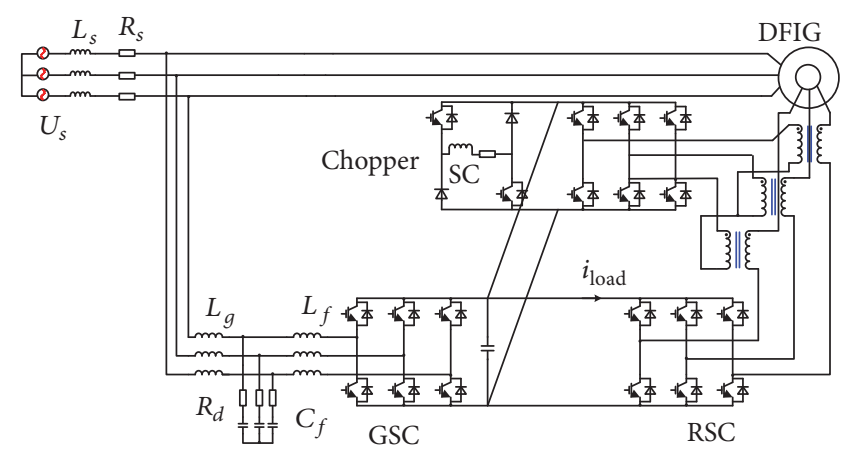

FIgURE 1: Topology of the whole system.

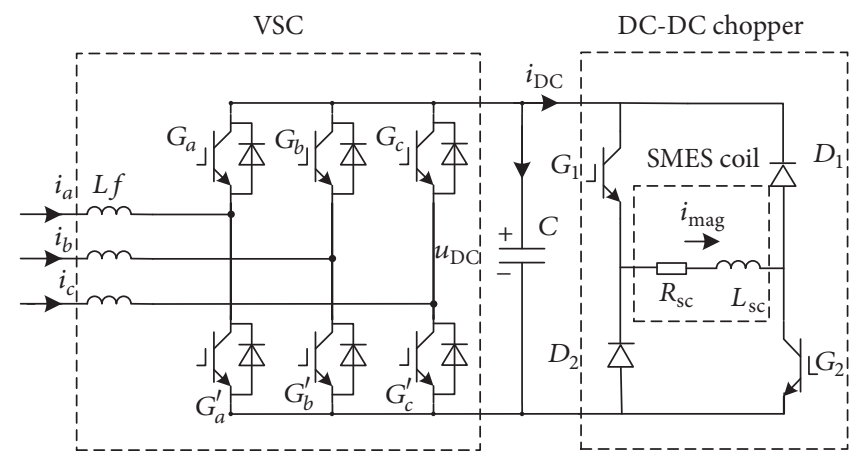

Figure 2: Topology of VSC-SMES.
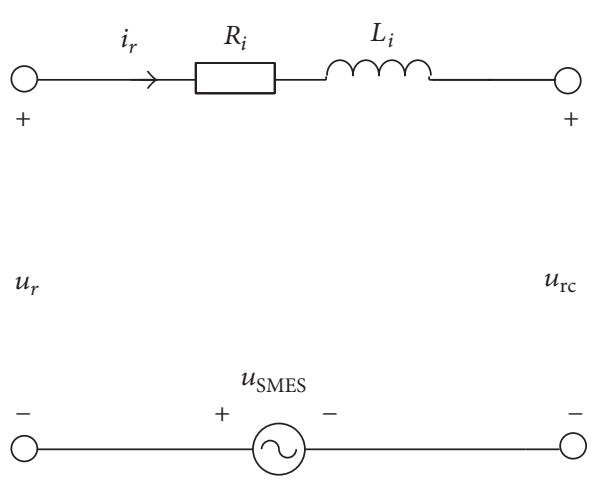

FIGURE 3: Equivalent circuit of the series SMES.

The topology of the whole system is shown in Figure 1. SMES is connected to the rotor side by a Voltage Source Converter (VSC). Topology of VSC-SMES is given in Figure 2. SMES can exchange active and reactive power with the system quickly and independently [13].

In the case of normal power supply, SMES is in standby mode. In this case, the series SMES will introduce resistance and reactance to DFIG. Thus the rotor voltage will not equate to rotor converter voltage. As shown in Figure $3, R_{i}$ and $L_{i}$ are the introduced resistance and reactance, respectively. In order to eliminate the influence of the rotor voltage by series SMES, the control of series SMES is to realize

$$
u_{r}=u_{\mathrm{rc}} .
$$




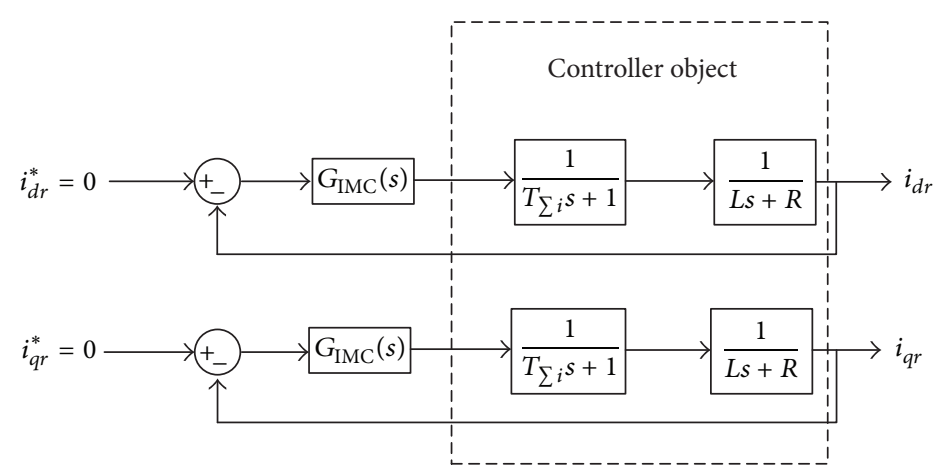

FIGURE 4: The current inner loop control stratagem.

When low voltage fault occurs, the SMES outputs the voltage to suppress the rotor back EMF voltage induced by stator; thus the rotor current is supposed to be zero when fault occurs and the rotor back EMF voltage induced by stator $u^{*}{ }_{r}$ can be shown as follows:

$$
\begin{aligned}
& u_{d r}^{*}=L_{m} \frac{d i_{d s}}{d t} \\
& u_{q r}^{*}=L_{m} \frac{d i_{q s}}{d t} .
\end{aligned}
$$

The stator current under grid fault after doing Laplace transform can be expressed as follows [15]:

$$
\begin{aligned}
i_{d s}= & \frac{\left(L_{s}+R_{s}\right) u_{d s}+\omega_{1} L_{s} u_{q s}}{\left(L_{s}{ }^{2} s^{2}+2 L_{s} R_{s} s+R_{s}{ }^{2}+\omega_{1}{ }^{2} L_{s}{ }^{2}\right)} \\
& -\frac{\left(L_{s} s^{2}+R_{s} s+\omega_{1}{ }^{2} L_{s}\right) L_{m} i_{d r}-R_{s} \omega_{1} L_{m} i_{q r}}{\left(L_{s}{ }^{2}{ }^{2}+2 L_{s} R_{s} s+R_{s}{ }^{2}+\omega_{1}{ }^{2} L_{s}{ }^{2}\right)} \\
i_{q s}= & \frac{\left(L_{s}+R_{s}\right) u_{q s}-\omega_{s} L_{s} u_{d s}}{\left(L_{s}{ }^{2} s^{2}+2 L_{s} R_{s} s+R_{s}{ }^{2}+\omega_{1}{ }^{2} L_{s}{ }^{2}\right)} \\
& -\frac{\left(L_{s} s^{2}+R_{s} s+\omega_{1}{ }^{2} L_{s}\right) L_{m} i_{q r}+R_{s} \omega_{1} L_{m} i_{d r}}{\left(L_{s}{ }^{2} s^{2}+2 L_{s} R_{s} s+R_{s}{ }^{2}+\omega_{1}{ }^{2} L_{s}{ }^{2}\right)} .
\end{aligned}
$$

Considering that $R_{s}^{2}, R_{s} \omega_{s} L_{m}$ are approximately 0 , the equation can be simplified as:

$$
\begin{aligned}
& i_{d s}=\frac{1}{L_{s}^{2}} \frac{L_{s} s+R_{s}}{s^{2}+2\left(R_{s} / L_{s}\right)+\omega_{1}^{2}} \cdot u_{d s}-\frac{L_{m}}{L_{s}} \cdot i_{d r} \\
& i_{q s}=\frac{1}{L_{s}{ }^{2}} \frac{\left(-L_{s} \omega_{1}\right)}{s^{2}+2\left(R_{s} / L_{s}\right)+\omega_{1}{ }^{2}} \cdot u_{d s}-\frac{L_{m}}{L_{s}} \cdot i_{q r} .
\end{aligned}
$$

According to the above analysis, if the rotor side converter could provide relative excitation voltage to $u^{*}{ }_{r}$, the low LVRT capability of DFIG will be enhanced. Thus set $u^{*}{ }_{r}$ as the reference voltage of VSC-SMES under grid fault. The VSCSMES reference voltage calculation process is presented in Figure 5.

\subsection{SMES Control}

3.1.1. VSC Control. As shown in Figure 2, through the park transformation, the mathematical model of VSC in the $d q$ reference frame is expressed as follows:

$$
\begin{aligned}
L \frac{d i_{d}}{d t} & =-R i_{d}+\omega L i_{q}+u_{s d}-u_{\mathrm{DC}} s_{d} \\
L \frac{d i_{q}}{d t} & =-R i_{q}-\omega L i_{d}+u_{s q}-u_{\mathrm{DC}} s_{q} \\
C \frac{d u_{\mathrm{DC}}}{d t} & =\frac{3}{2}\left(i_{q} s_{q}+i_{d} s_{d}\right)-i_{\text {chopper }} .
\end{aligned}
$$

The current inner loop control of VSC adopts the internal model control strategy [14]; the control block diagram is shown in Figure 4. The closed-loop transfer function of the current inner loop is

$$
W_{c i}(s)=\frac{1}{T_{f}^{2} s^{2}+2 \xi T_{f} s+1} .
$$

For achieving the purpose of rapid response of the current inner loop, let $T_{f}$ be equal to $0.0002 \mathrm{~s}$.

3.1.2. DC-DC Chopper Control. Chopper has two basic modes of operation: (1) magnetizing mode; (2) releasing magnetic mode. The mathematical model of chopper is

$$
\begin{gathered}
L_{\mathrm{sc}} \frac{d i_{\mathrm{mag}}}{d t}=-R_{\mathrm{sc}} i_{\mathrm{mag}}+\left(D_{1}+D_{2}-1\right) u_{\mathrm{DC}} \\
C \frac{d u_{\mathrm{DC}}}{d t}=-\left(D_{1}+D_{2}-1\right) i_{\mathrm{mag}}+i_{\mathrm{DC}},
\end{gathered}
$$

where $i_{\text {mag }}$ is the current of magnet and $D$ is the switch state of each switch; if switch 1 is on, $D_{1}$ is equal to 1 .

In normal operation, the control of chopper is to limit the magnet current in a setting scale. When low voltage fault happens, the control of chopper is to maintain the stability of the DC voltage. The control strategy of SMES is shown in Figure 5.

3.2. RSC Control. In normal operation, the control of $d / q$ component of rotor current is to control the active and 


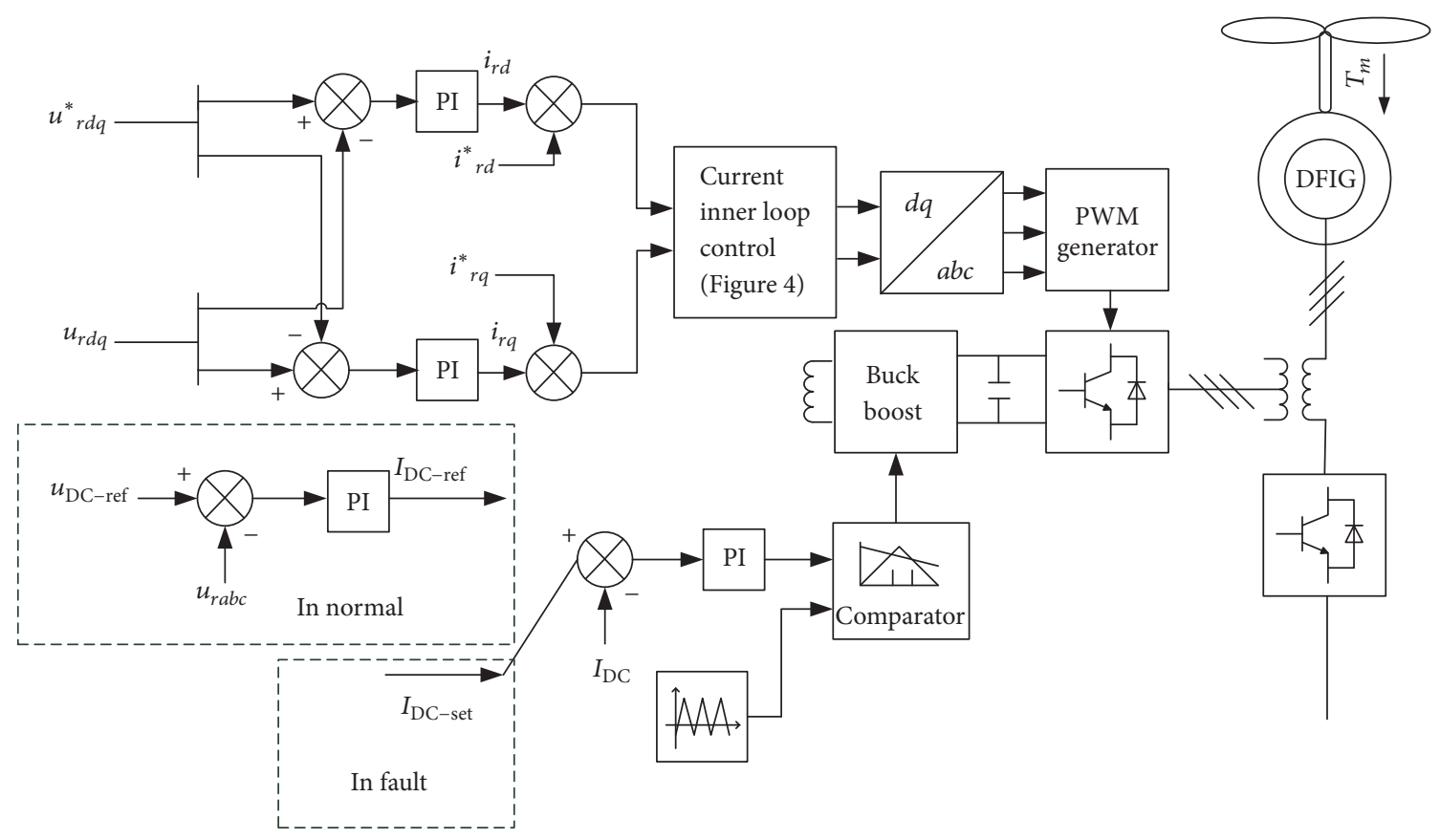

FIgURE 5: The control stratagem for SMES.
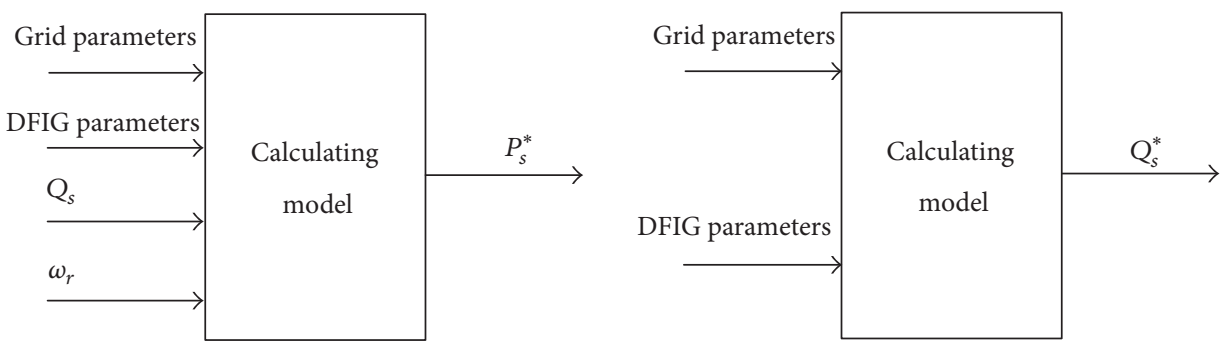

FIGURE 6: Reference power calculation model of DFIG.

reactive power of DFIG. Generally, the purpose of control system is to obtain the max wind power.

The essence of the maximum wind energy tracking is to control the DFIG output active power and control electromagnetic torque to achieve the best speed control. When the mechanical output of the wind turbine achieves maximum output power, the reference active power of DFIG $P_{s}^{*}$ is equal to stator power $P_{s}$, as shown as follows:

$$
P_{s}^{*}=\frac{1}{1-s}\left(P_{\max }-P_{\mathrm{ms}}\right)-P_{\text {cus }},
$$

where $P_{\mathrm{ms}}$ is the mechanical loss of wind turbine and $P_{\text {cus }}$ is the copper loss of stator, which is related to $I_{s}$ and $R_{s}$. After doing identity transformation, (9) can be expressed as follows:

$$
\begin{aligned}
& A\left(P_{s}^{*}\right)^{2}+B P_{s}^{*}+C=0 \\
& A=\frac{R_{s}}{3 U_{s}^{2}}, B=1, C=\frac{1}{s-1}\left(k_{w} \omega_{w}^{3}-P_{m s}\right)+\frac{R_{s}}{3 U_{s}^{2}} Q_{s} .
\end{aligned}
$$

The reactive reference power value $Q_{s}^{*}$ can be calculated by achieving the lowest loss of DFIG or improving the system's ability to regulate power. In this paper, $Q_{s}^{*}$ is calculated to achieve the lowest loss of DFIG. Thus the expression of $Q_{s}^{*}$ is shown as follows:

$$
Q_{s}^{*}=-\frac{3 X_{s} R_{r} U_{s}^{2}}{R_{s} X_{m}^{2}+R_{r} R_{s}^{2}+R_{r} X_{s}^{2}} .
$$

The reference power calculation model of DFIG is shown in Figure 6.

When a fault occurs, the control strategy of rotor converter is irrelevant. Considering SMES will absorb the wind energy, $i^{*}{ }_{d r}$ and $i^{*}{ }_{q r}$ can be set to zero to prevent the energy through the converter. Thus, the capacitor in DC side will not absorb a lot of energy and its voltage will not increase sharply. The control stratagem of RSC, in normal situation and when voltage drop happens, is shown in Figure 7.

3.3. GSC Control. The purpose of GSC control is to maintain DC capacitor voltage stability and control the factor of input 


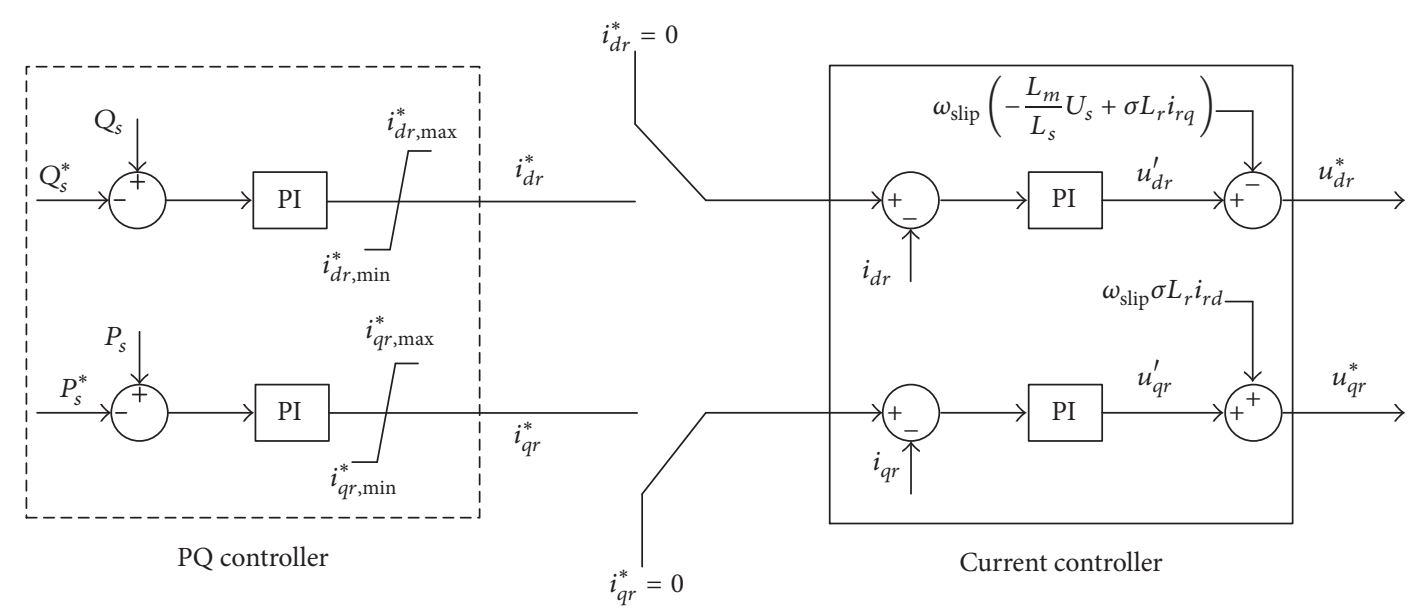

FIgURE 7: Control block diagram of the RSC.

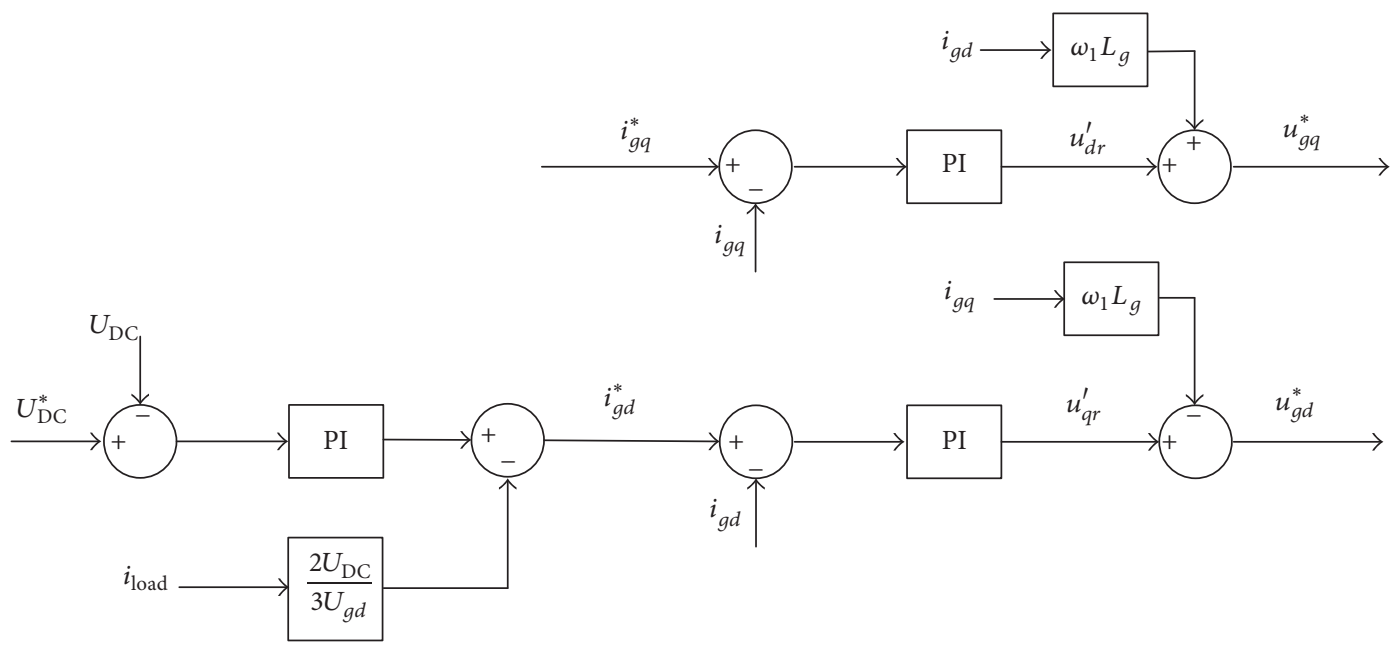

FIGURE 8: Control block diagram of the GSC.

power. The GSC control system is divided into two parts: the outer voltage loop and the inner current loop, which is shown in Figure 8. Compensation of load disturbances is achieved by feedforward of the load current $i_{\text {load }}$. System is decoupled by introduced current state feedback $w_{1} L_{g} i_{g d}, w_{1} L_{g} i_{g q}$.

\section{Economic Analysis}

Compared to other energy storage devices, SEMS has the advantage of high response speed, high efficiency, highpower density, and high cycle life characteristics. But the application of SMES in DFIG will increase the cost of the system. Therefore, the capital cost of SMES applied in DFIG is an indispensable part of DFIG's technical performance. In terms of energy storage devices, the capital costs contain energy cost $\$ / \mathrm{kWh}$, power cost $\$ / \mathrm{kW}$, and cycle cost. As the energy storage device is used in DFIG, high-power characteristic is necessary. The power costs of SMES are less than their energy costs, and this is an indication that they are suitable for high-power applications. Table 1 shows the cost comparison for the storage technologies [16]. As can be seen from the table, SMES has a lower power cost compared to pumped-hydro storage, lithium-ion batteries and other energy storage devices. In addition, the long life of SMES makes it possible to participate in the protection of the entire life of the DFIG. In general, considering the economic and other technical performances, SMES is a good choice for ESD in DFIG.

\section{Simulation Analysis and Conclusion}

The simulations are carried out in MATLAB/Simulink. The simulation parameters are shown in Table 2. The simulation parameters of SMES are shown in Table 3. The purpose of the simulation is to observe the performance of the back-to-back converter when the grid fault occurs. 


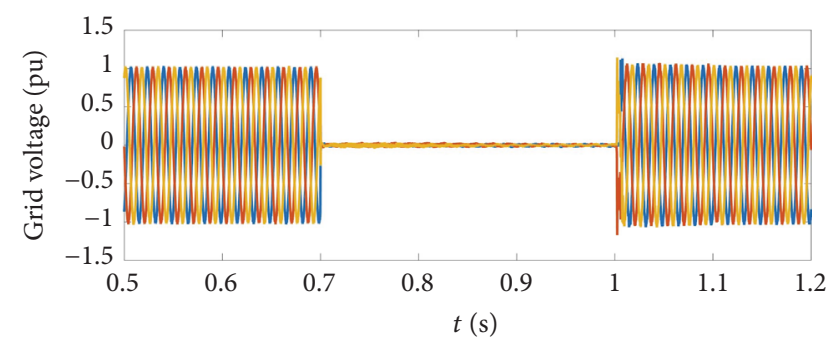

(a)

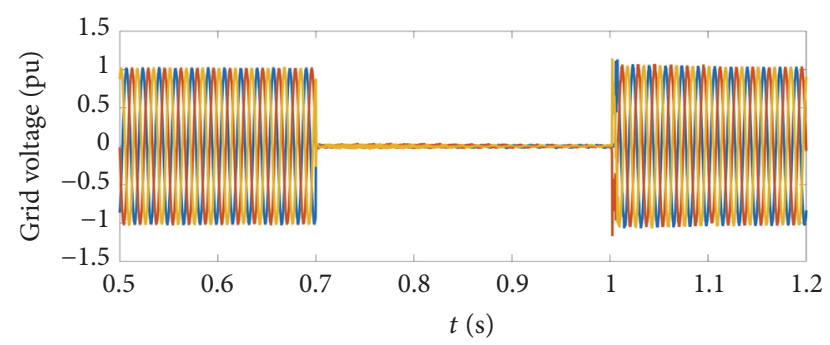

(b)

FIGURE 9: The grid voltage.

TABLE 1: Cost comparison for the storage technologies.

\begin{tabular}{lcccc}
\hline ESD & Capacity & Life & Power cost $(\$ / \mathrm{kW})$ & Energy cost $(\$ / \mathrm{kWh})$ \\
\hline Pumped-hydro storage & $100-2000 \mathrm{MW}$ & $>20$ years & $2000-4300$ & $10-100$ \\
Compressed-air energy storage & $100-300 \mathrm{MW}$ & $>20$ years & $400-1000$ & $2-50$ \\
Flywheel energy storage & $5 \mathrm{~kW}-1.5 \mathrm{MW}$ & $>15$ years & $250-350$ & $1000-10000$ \\
Lithium-ion batteries & $1-1000 \mathrm{~kW}$ & 3000 cycles & $1000-3000$ & $1000-3800$ \\
Supercapacitors & $1-100 \mathrm{~kW}$ & $>50000$ cycles & $100-300$ & $300-2000$ \\
Superconducting magnetic energy storage & $10-500 \mathrm{~kW}$ & $>20$ years & $200-400$ & $500-1000$ \\
Vanadium redox battery & $<10 \mathrm{MW}$ & $10-30$ years & $600-1500$ & $150-1000$ \\
\hline
\end{tabular}

TABLE 2: DFIG parameters.

\begin{tabular}{lcc}
\hline Symbol & Name & Quantity \\
\hline$S_{N}$ & Capacity & $1.5 \mathrm{MW}$ \\
$f_{N}$ & System frequency & $60 \mathrm{~Hz}$ \\
$R_{s}$ & Stator resistance & $0.016 \mathrm{p} . \mathrm{u}$. \\
$L_{l s}$ & Stator leakage inductance & 0.16 p.u. \\
$R_{r}$ & Rotor resistance & 0.016 p.u. \\
$L_{l r}$ & Rotor leakage inductance & 0.16 p.u. \\
$L_{m}$ & Magnetizing inductance & 2.9 p.u \\
$S_{b}$ & Base capacity & $1.5 / 0.9 \mathrm{MVA}$ \\
$f_{b}$ & Base frequency & $60 \mathrm{~Hz}$ \\
$V_{s_{-} \text {nom }}$ & Base stator voltage $\left(V_{\text {rms }}\right)$ & $575 \mathrm{~V}$ \\
$V_{r_{-} \text {nom }}$ & Base rotor voltage $\left(V_{\text {rms }}\right)$ & $1975 \mathrm{~V}$ \\
\hline
\end{tabular}

TABLE 3: SMES parameters.

\begin{tabular}{lc}
\hline Parameter & Value \\
\hline HTS material & Bi 2223 \\
Capacity & $40 \mathrm{~kJ} / 600 \mathrm{~kW}$ \\
Magnet inductance $(L)$ & $0.5 \mathrm{H}$ \\
Magnet resistance & $2 \times 10^{-5} \Omega$ \\
Filter capacitance $(C)$ & $0.02 \mathrm{~F}$ \\
Series transformer ratio & 1 \\
Transformer resistance & $1 \times 10^{-4} \Omega$ \\
\hline
\end{tabular}

The transient grid voltage fault occurs at $0.7 \mathrm{~s}$ and lasts for $300 \mathrm{~ms}$. The grid voltage during fault drops to 0 . The grid voltage is shown in Figure 9. Figures 10 and 11 compare the currents of stator converter and rotor converter with and without SMES. When there is no SMES, in the moment of low voltage faults, the overcurrent of the stator and rotor side converters is almost five times larger than the normal operating range. With the proposed method, the currents of back-to-back converters are always in the affordable range. Moreover, as shown in Figure 13, the DC capacitor voltage is well suppressed during the fault. The output voltage of SMES in $d / q$ frame is shown in Figure 12. The base voltage is the same as base rotor voltage. Figure 14 shows the transient SMES current response.

Compared to traditional control stratagems, the new control strategy with SMES can suppress the overcurrent in stator and rotor within the affordable range even when grid voltage drops to 0 . The DC bus voltage can also be limited effectively.

This paper presents a new control stratagem to enhance the LVRT capability of DFIG with series SMES. By controlling the SMES output voltage with the proposed controller, 


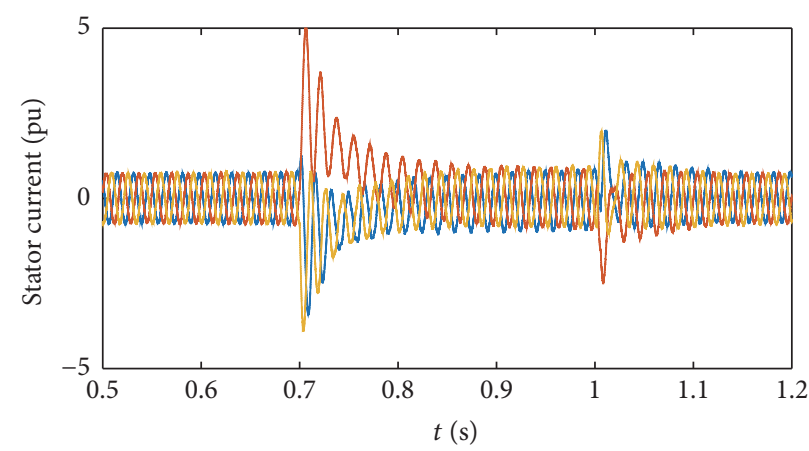

(a) The current of stator converter with SMES

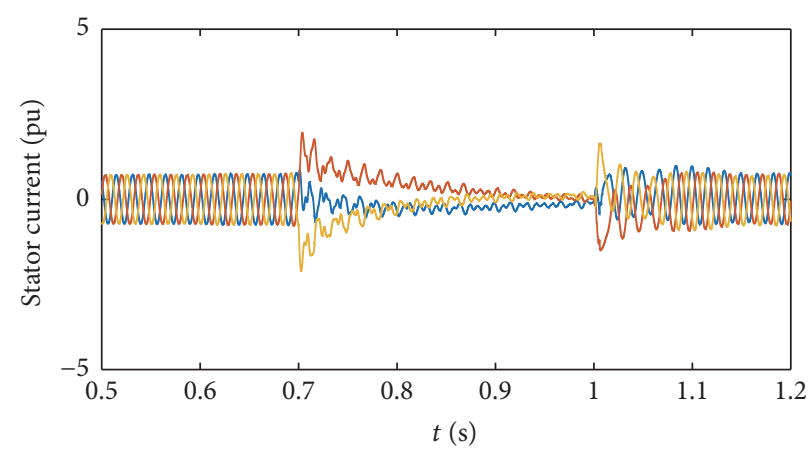

(b) The current of stator converter without SMES

Figure 10

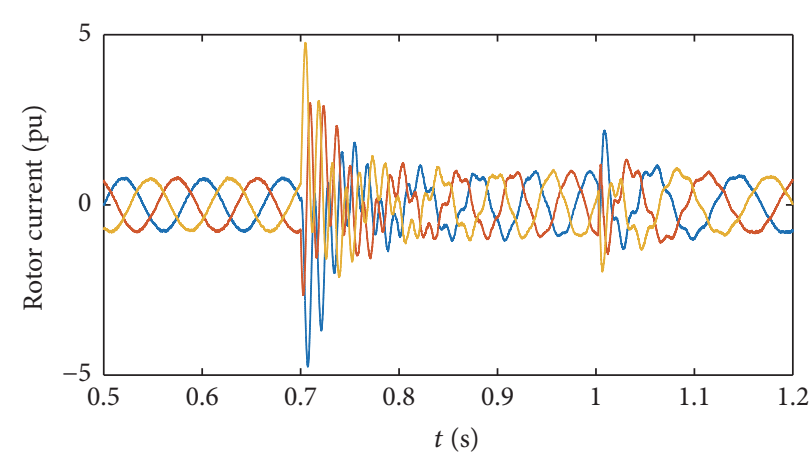

(a) The current of rotor converter with SMES

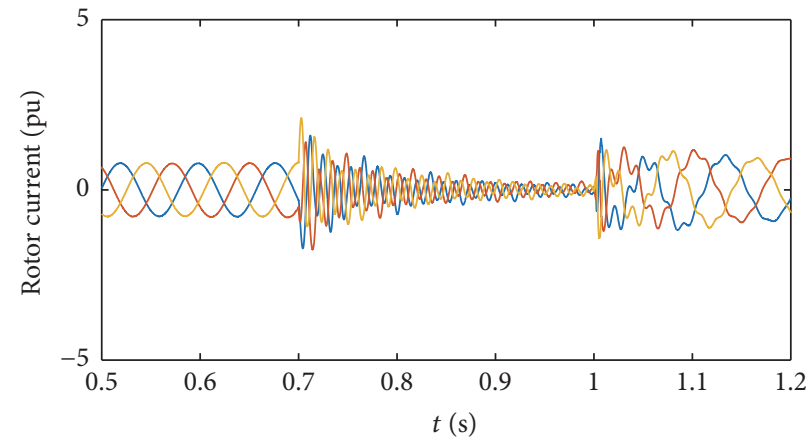

(b) The current of rotor converter without SMES

FIGURE 11

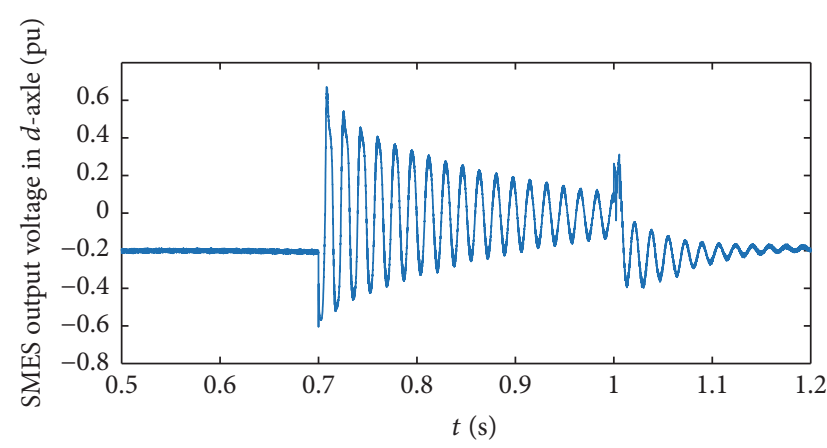

(a)

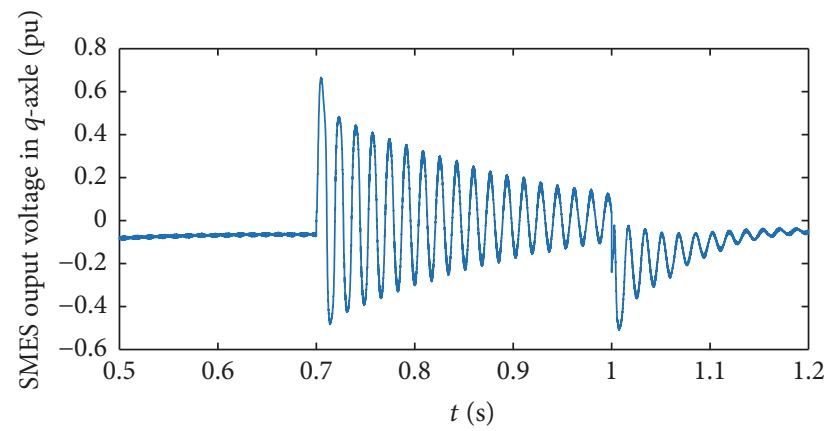

(b)

FIGURE 12: The SMES output voltage.

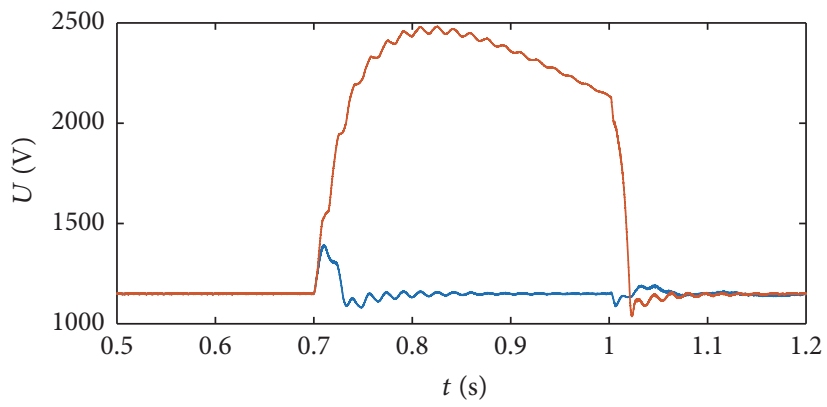

Without SMES

With SMES

Figure 13: The DC voltage. 


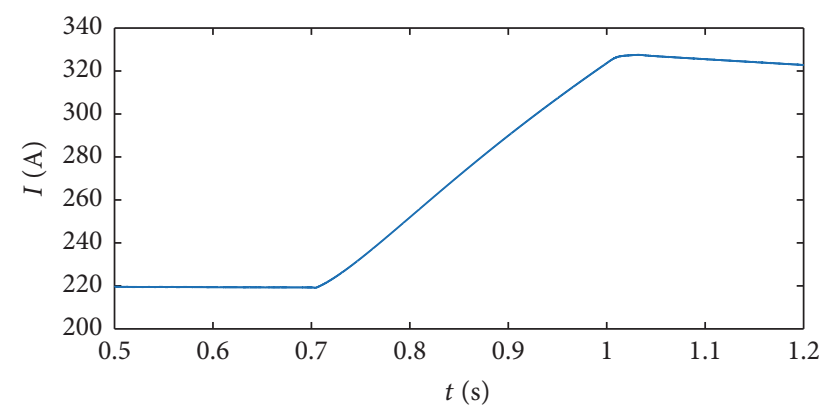

FIGURE 14: The magnet current of SMES.

the converter currents and capacitor voltage in fault are suppressed effectively. The method has been validated by simulations in MATLAB/Simulink.

\section{Conflicts of Interest}

There are no conflicts of interest regarding the publication of this paper.

\section{References}

[1] Y.-W. Shen, D.-P. Ke, W. Qiao, Y.-Z. Sun, D. S. Kirschen, and C. Wei, "Transient reconfiguration and coordinated control for power converters to enhance the LVRT of a DFIG wind turbine with an energy storage device," IEEE Transactions on Energy Conversion, vol. 30, no. 4, pp. 1679-1690, 2015.

[2] J. Liu, H. Zhang, B. Yang, and Y. Min, "Fault ride through under unbalanced voltage sag of wind energy conversion system using superconducting magnetic energy storage," in Proceedings of the 2nd IEEE International Future Energy Electronics Conference, Taipei, Taiwan, November 2015.

[3] J. Niiranen, "Voltage dip ride through of a doubly-fed generator equipped with an active crowbar," in Proceedings of the Nordic Wind Power Conference Nwpc, 2004.

[4] L.-L. Sun, P. Yang, and Y. Wang, "Simulation research for LVRT of DFIG based on rotor active crowbar protection," in Proceedings of the International Conference on Sustainable Power Generation and Supply, SUPERGEN 2012, pp. 1-7, Hangzhou, China, September 2012.

[5] P. Su and K.-S. Zhang, "Simulation research for LVRT of DFIG with active IGBT Crowbar," Power System Protection and Control, vol. 38, no. 23, pp. 164-171, 2010.

[6] J. Hu, H. Wang, Y. He, and L. Xu, "Improved rotor current control of wind turbine driven doubly fed induction generators during network unbalance," in Proceedings of the 1st International Conference on Sustainable Power Generation and Supply, SUPERGEN '09, pp. 1-7, Nanjing, China, April 2009.

[7] T. K. A. Brekken and N. Mohan, "Control of a doubly fed induction wind generator under unbalanced grid voltage conditions," IEEE Transactions on Energy Conversion, vol. 22, no. 1, pp. 129$135,2007$.

[8] A. G. Abo- Khalil, D.-C. Lee, and J.-I. Jang, "Control of back-toback PWM converters for DFIG wind turbine systems under unbalanced grid voltage," in Proceedings of the 2007 IEEE International Symposium on Industrial Electronics, ISIE 2007, pp. 2637-2642, Vigo, Spain, June 2007.
[9] C. Abbey and G. Joos, "Supercapacitor energy storage for wind energy applications," IEEE Transactions on Industry Applications, vol. 43, no. 3, pp. 763-776, 2007.

[10] B. S. Borowy and Z. M. Salameh, "Dynamic response of a stand-alone wind energy conversion system with battery energy storage to a wind gust," IEEE Transactions on Energy Conversion, vol. 12, no. 1, pp. 73-78, 1997.

[11] A. Yazdani, "Islanded operation of a doubly-fed induction generator (DFIG) wind-power system with integrated energy storage," in Proceedings of the 2007 IEEE Canada Electrical Power Conference, EPC 2007, pp. 153-159, Montreal, Canada, October 2007.

[12] J. Shi, Y. Tang, Y. Xia, L. Ren, and J. Li, "SMES based excitation system for doubly-fed induction generator in wind power application," IEEE Transactions on Applied Superconductivity, vol. 21, no. 3, pp. 1105-1108, 2011.

[13] Y. Zhang, Y. Tang, J. Li, J. Shi, and L. Ren, "Superconducting magnet based VSC suitable for interface of renewable power sources," IEEE Transactions on Applied Superconductivity, vol. 20, no. 3, pp. 880-883, 2010.

[14] W. Guo, L. Xiao, and S. Dai, "Enhancing low-voltage ridethrough capability and smoothing output power of DFIG with a superconducting fault-current limiter-magnetic energy storage system," IEEE Transactions on Energy Conversion, vol. 27, no. 2, pp. 277-295, 2012.

[15] F. K. A. Lima, A. Luna, P. Rodriguez, E. H. Watanabe, and F. Blaabjerg, "Rotor voltage dynamics in the doubly fed induction generator during grid faults," IEEE Transactions on Power Electronics, vol. 25, no. 1, pp. 118-130, 2010.

[16] D. O. Akinyele and R. K. Rayudu, "Review of energy storage technologies for sustainable power networks," Sustainable Energy Technologies and Assessments, vol. 8, pp. 74-91, 2014. 


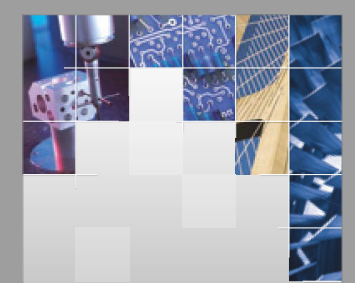

\section{Enfincering}
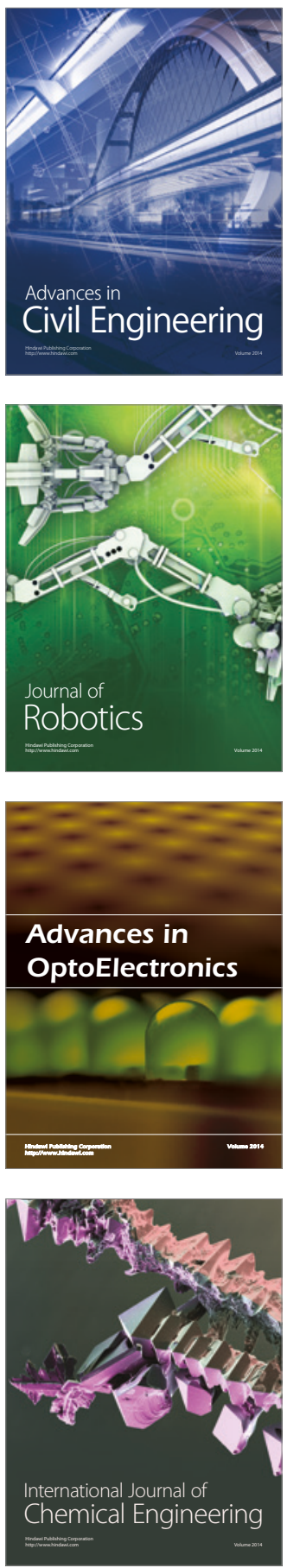

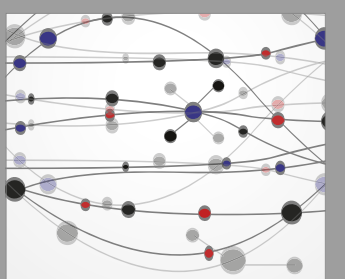

The Scientific World Journal

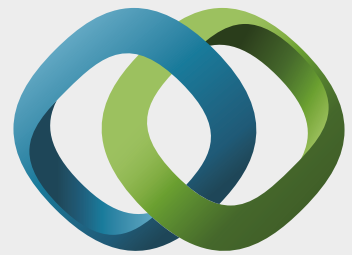

\section{Hindawi}

Submit your manuscripts at

https://www.hindawi.com
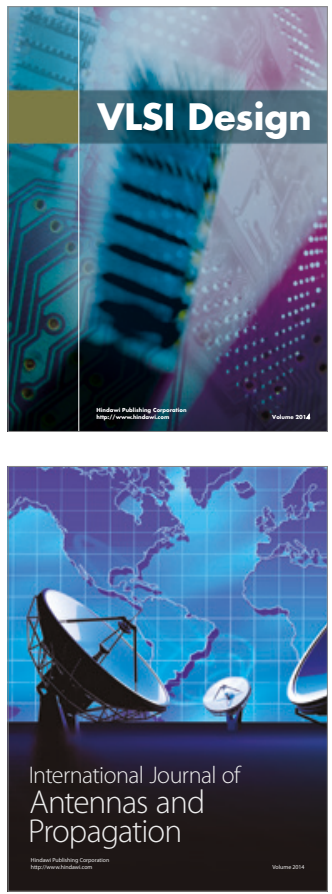

\section{Rotating}

Machinery
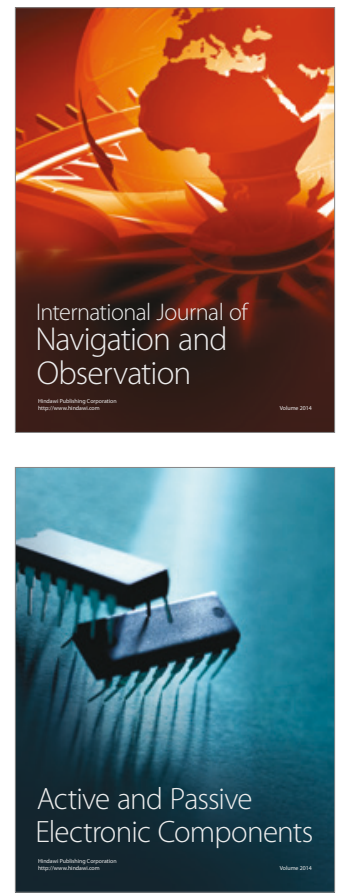
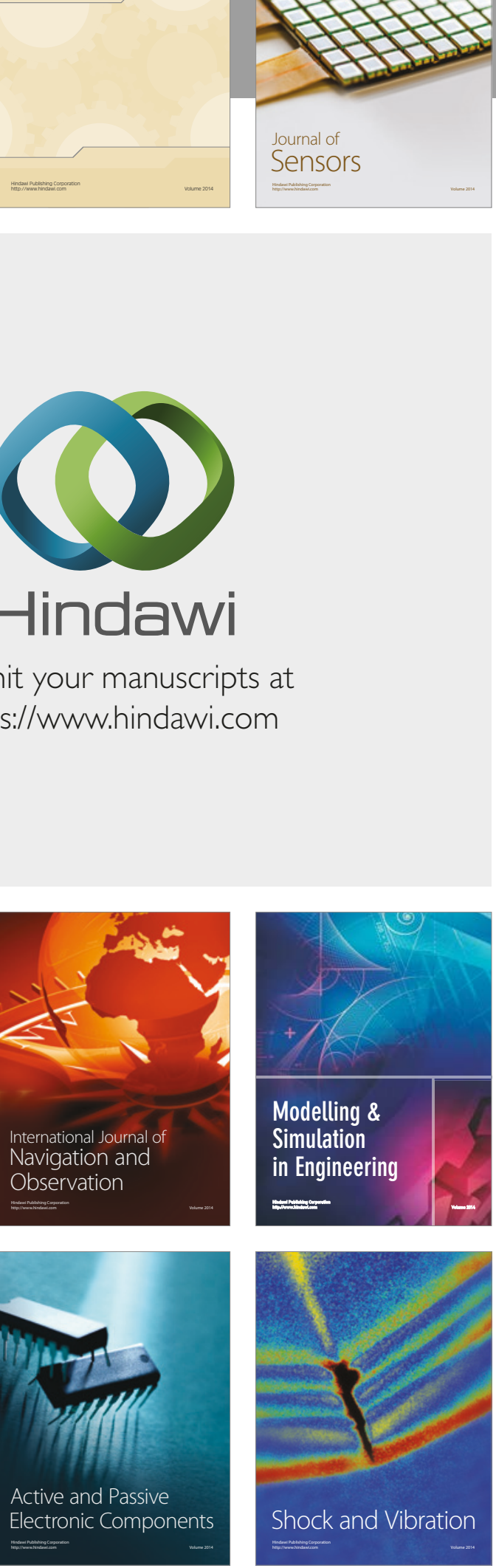
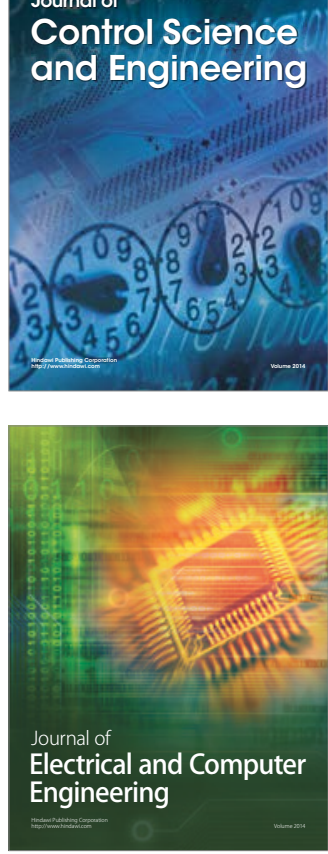

Distributed

Journal of

Control Science

and Engineering
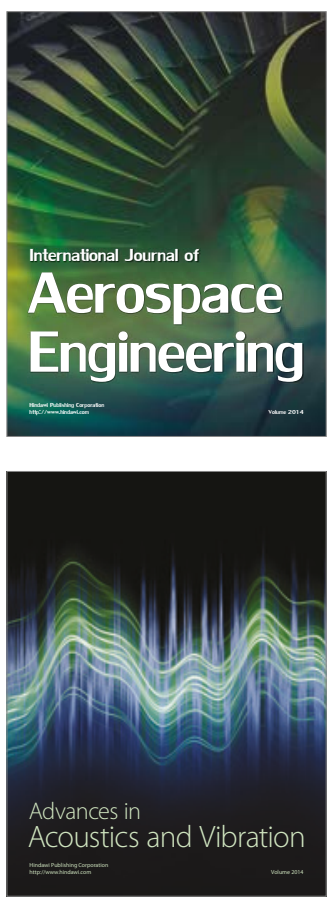

Sensor Networks 